\title{
AVALIAÇÃO DA QUALIDADE DE MANGAS 'TOMMY ATKINS' MINIMAMENTE PROCESSADAS ${ }^{1}$
}

\author{
BRÍGIDA MONTEIRO VILAS BOAS², ELISÂNGELA ELENA NUNES ${ }^{3}$, FABRÍCIO VILELA ANDRADE FIORINI ${ }^{4}$, \\ LUIZ CARLOS DE OLIVEIRA LIMA ${ }^{5}$, EDUARDO VALÉRIO DE BARROS VILAS BOAS ${ }^{6}$, \\ ANA HELENA ROMANIELLO COELHO ${ }^{7}$
}

\begin{abstract}
RESUMO - Visto que a popularidade de frutas e hortaliças minimamente processadas tem aumentado nos últimos anos devido aos aspectos de conveniência e qualidade, este trabalho teve por objetivo avaliar o efeito do ácido cítrico $1 \%$, ácido ascórbico $1 \%$ e cloreto de cálcio $1 \%$ na conservação de mangas 'Tommy Atkins' minimamente processadas, armazenadas sob atmosfera modificada ativa $\left(5 \% \mathrm{O}_{2}+5 \% \mathrm{CO}_{2}\right)$ e refrigeração por 12 dias. Foram realizadas as seguintes análises: acidez titulável, $\mathrm{pH}$, sólidos solúveis totais, açúcares solúveis totais, vitamina $\mathrm{C}$ total, análise sensorial (sabor) e análises microbiológicas (contagem de fungos filamentosos e leveduras e coliformes a 35 e $45^{\circ} \mathrm{C}$ ). Pode-se concluir que os tratamentos com ácido cítrico $1 \%$, ácido ascórbico $1 \% \mathrm{e} \mathrm{CaCl}_{2} 1 \%$ não influenciam na vida de prateleira das mangas 'Tommy Atkins' minimamente processadas. De acordo com a análise sensorial e microbiológica, a vida útil é de 12 dias a $5^{\circ} \mathrm{C}$.
\end{abstract}

Termos para indexação: Mangifera indica L., processamento mínimo, vida de prateleira

\section{QUALITY EVALUATION OF FRESH-CUT 'TOMMY ATKINS' MANGOES}

\begin{abstract}
Since the popularity of fresh-cut fruits and vegetables has increased lately, due to the convenience and quality aspects, chemical modifications were investigated, in addition to sensory and microbiological aspects of fresh-cut the 'Tommy Atkins' mangoes were treated with $1 \%$ citric acid, $1 \%$ ascorbic acid and $1 \%$ calcium chloride stored under active modified atmospheres $\left(5 \% \mathrm{O}_{2}+5 \% \mathrm{CO}_{2}\right)$ and refrigerated for 12 days. The following analyses were done: titratable acidity, $\mathrm{pH}$, total soluble solids, total soluble sugars, $\mathrm{C}$ vitamin, sensory analysis (taste) and microbiological analyses (filamentous fungus and yeast counting and coliforms at $35 \mathrm{e} 45^{\circ} \mathrm{C}$ ). It was concluded that the treatments with $1 \%$ citric acid, $1 \%$ ascorbic acid and $1 \% \mathrm{CaCl}_{2}$ didn't influence the shelf-life of the fresh-cut 'Tommy Atkins' mangoes. According to the sensory and microbiological analyses the useful life is 12 days at $5^{\circ} \mathrm{C}$.
\end{abstract}

Index terms: Mangifera indica $\mathrm{L}$., fresh-cut, shelf life

Produtos minimamente processados são definidos como qualquer fruta ou hortaliça ou qualquer combinação delas, que foi alterado fisicamente a partir de sua forma original, embora mantenha o seu estado fresco. Independentemente do produto, ele é selecionado, lavado, descascado e cortado num produto $100 \%$ aproveitável, que é embalado ou pré-embalado com o intuito de oferecer aos consumidores: frescor, conveniência e qualidade nutricional (IFPA, 2002).

O dano físico ou ferimento causado pelo descascamento e corte durante o processamento mínimo aumenta a taxa de respiração e a produção de etileno pelos tecidos em minutos, promovendo reações químicas e bioquímicas responsáveis por modificações da qualidade sensorial (cor, sabor, aroma e textura) e nutricional (teor vitamínico) (Cantwell \& Suslow, 2002). Em decorrência da elevação da atividade respiratória, há decréscimo nas reservas energéticas dos tecidos. Os principais substratos utilizados são os açúcares livres e os ácidos orgânicos, sendo que a redução na concentração dos mesmos reflete nas perdas das características de sabor do produto (Chitarra, 2000). Sendo assim, o uso de tratamentos químicos, de atmosfera modificada e de refrigeração adequada tem sido utilizado para preservar a qualidade destes produtos e aumentar o seu período de conservação.

Este trabalho teve por objetivo avaliar o efeito do ácido cítrico $1 \%$, ácido ascórbico $1 \%$ e cloreto de cálcio $1 \%$ na conservação de mangas 'Tommy Atkins' minimamente processadas durante 12 dias de armazenamento sob refrigeração $\left(5 \pm 0,5^{\circ} \mathrm{C}\right.$ e $80-90 \%$ UR) e atmosfera modificada ativa $\left(5 \% \mathrm{O}_{2}+5 \% \mathrm{CO}_{2}\right)$.

As mangas 'Tommy Atkins' foram provenientes de PetrolinaPE, e adquiridas no comércio local de Lavras - MG. As frutas usadas no processamento mínimo foram selecionadas de acordo com a firmeza da polpa entre $29 \mathrm{~N}$ e $38 \mathrm{~N}$. O experimento foi realizado no Laboratório de
Bioquímica de Frutos do Departamento de Ciência dos Alimentos da Universidade Federal de Lavras (UFLA), Lavras-MG, em condições higiênicas. Todos os utensílios foram previamente lavados e sanificados com soluções de hipoclorito de sódio a 200 ppm e etanol 70\% (v/v). Os operadores usavam luvas, gorros, máscaras e aventais.

As mangas foram lavadas com detergente neutro e sanificadas em solução de hipoclorito de sódio a 300 ppm por 15 minutos. Em seguida, foram descascadas manualmente, a polpa separada longitudinalmente do caroço e cortada em pedaços ( $20 \mathrm{~mm} \times 30 \mathrm{~mm})$. Estes foram imersos, por 4 minutos, nas seguintes soluções: controle (água destilada), ácido cítrico $1 \%$, ácido ascórbico $1 \%$, cloreto de cálcio $1 \%\left(\mathrm{CaCl}_{2} 1 \%\right)$. Após a imersão, os pedaços de manga foram colocados em peneira plástica, por 5 minutos, para a retirada do excesso de líquido acumulado. Em seguida, foram acondicionados em embalagens de polipropileno (PP) e estas seladas com filme flexível de polietileno + polipropilenos $60 \mu \mathrm{m}$ de espessura, havendo a injeção da mistura gasosa, $5 \% \mathrm{O}_{2}+5 \% \mathrm{CO}_{2}$, utilizando-se de Seladora de Bandejas - AP340 (TecMaq). O produto foi armazenado em câmara fria $\mathrm{a} 5 \pm 0,5^{\circ} \mathrm{C}$ e umidade relativa (UR) $85 \pm 5 \%$ por 12 dias e as análises realizadas a cada dois dias. Foram avaliadas: acidez titulável (Instituto Adolfo Lutz, 1985), pH (AOAC, 1992), sólidos solúveis totais (AOAC, 1992), açúcares solúveis totais (Dische, 1962) e vitamina C total (Strohecker \& Henning, 1967). A análise sensorial foi feita por nove julgadores treinados que avaliaram o sabor das mangas minimamente processadas com base numa escala hedônica de 9 pontos: 9. extremamente boa; 8 . muito boa; 7. moderadamente boa; 6 . ligeiramente boa; 5 . indiferente; 4 . ligeiramente ruim; 3 . moderadamente ruim; 2 . muito ruim, e 1. extremamente ruim. Os julgadores em cabines individuais com luz vermelha para mascarar a cor recebiam as quatro amostras simultaneamente em duplicata referentes aos tratamentos. A análise

${ }^{1}$ (Trabalho 037/2004). Recebido: 02/04/2004. Aceito para publicação: 25/10/2004.

${ }^{2}$ Engenheira Agrônoma, Msc, doutoranda em Ciência dos Alimentos, Departamento de Ciência dos Alimentos - DCA, Universidade Federal de Lavras - UFLA, Lavras, MG Caixa postal: 37 tel. (35) 3821-5173 bmvboas@hotmail.com

${ }^{3}$ Farmacêutica-Bioquímica, Msc, doutoranda em Ciência dos Alimentos, DCA-UFLA elinunes@ufla.br

${ }^{4}$ Graduando em Agronomia, UFLA fabriciovaf@hotmail.com

${ }^{5}$ Farmacêutico-Bioquímico, Prof. Dr. em Ciência dos Alimentos, DCA-UFLAlcolima@ufla.br

${ }^{6}$ Engenheiro Agrônomo, Prof. Dr. em Ciência dos Alimentos, DCA-UFLA evbvboas@ufla.br

${ }^{7}$ Engenheira Agrônoma, Dra em Ciência dos Alimentos, DCA-UFLA

Rev. Bras. Frutic., Jaboticabal - SP, v. 26, n. 3, p. 540-543, Dezembro 2004 
TABELA 1 - Valores médios de acidez titulável de mangas ‘Tommy Atkins' minimamente processadas.

\begin{tabular}{lccccccc}
\hline Tratamentos & \multicolumn{7}{c}{ Tempos de armazenamento (dias) } \\
\cline { 2 - 7 } & 0 & 2 & 4 & 6 & 8 & 10 & 12 \\
\hline Controle & $0,235 \mathrm{a}$ & $0,235 \mathrm{~b}$ & $0,224 \mathrm{~b}$ & $0,235 \mathrm{a}$ & $0,203 \mathrm{a}$ & $0,181 \mathrm{a}$ & $0,171 \mathrm{a}$ \\
Ác. cítrico $1 \%$ & $0,235 \mathrm{a}$ & $0,256 \mathrm{ab}$ & $0,245 \mathrm{~b}$ & $0,235 \mathrm{a}$ & $0,224 \mathrm{a}$ & $0,213 \mathrm{a}$ & $0,181 \mathrm{a}$ \\
Ác. ascórbico $1 \%$ & $0,277 \mathrm{a}$ & $0,288 \mathrm{a}$ & $0,309 \mathrm{a}$ & $0,235 \mathrm{a}$ & $0,213 \mathrm{a}$ & $0,203 \mathrm{a}$ & $0,192 \mathrm{a}$ \\
$\mathrm{CaCl}_{2} 1 \%$ & $0,245 \mathrm{a}$ & $0,299 \mathrm{a}$ & $0,320 \mathrm{a}$ & $0,245 \mathrm{a}$ & $0,213 \mathrm{a}$ & $0,192 \mathrm{a}$ & $0,181 \mathrm{a}$ \\
\hline
\end{tabular}

Médias seguidas de mesma letra na coluna não diferem entre si, pelo teste de Tukey $(\mathrm{p}<0,05)$

microbiológica (ICMSF,1982) foi realizada quantificando Coliformes a 35 e $45^{\circ} \mathrm{C}$ pela técnica do número mais provável - NMP. A contagem de fungos filamentosos e leveduras foi realizada pelo método de plaqueamento em profundidade, utilizando meio de batata dextrose ágar (BDA) acidificado com ácido tartárico a $10 \%$. Os resultados foram expressos em UFC (unidades formadoras de colônia). $\mathrm{g}^{-1}$ de polpa.

$\mathrm{O}$ experimento foi conduzido em delineamento inteiramente casualizado, com 3 repetições, em esquema fatorial $4 \times 7$, constituído pelos fatores tratamentos químicos (controle, ácido cítrico $1 \%$, ácido ascórbico $\left.1 \%, \mathrm{CaCl}_{2} 1 \%\right)$ e tempos de armazenamento $(0 ; 2 ; 4 ; 6 ; 8 ; 10$; 12 dias). A parcela experimental foi constituída por uma bandeja (15,0 $\mathrm{cm}$ de comprimento $\mathrm{x} 11,5 \mathrm{~cm}$ de largura $\times 4,5 \mathrm{~cm}$ de altura) contendo aproximadamente $130 \mathrm{~g}$ de manga.

Houve interação significativa entre os fatores tratamentos químicos e tempo de armazenamento para a variável acidez titulável (AT). A diferença estatística foi detectada apenas no segundo e quarto dias de armazenamento. Em ambos os tempos, as mangas minimamente processadas, tratadas com ácido ascórbico $1 \%$ e $\mathrm{CaCl}_{2} 1 \%$, mostraram maiores teores de acidez que o controle (Tabela 1). A AT dos pedaços de manga ‘Tommy Atkins' sofreu decréscimo durante o armazenamento. Donadon et al. (2001) também evidenciaram tendência de redução nos teores de acidez titulável ao longo de 14 dias de armazenamento a $3^{\circ} \mathrm{C}$ em pedaços de manga da mesma cultivar embalados em copos plásticos de polietileno de baixa densidade. Os valores encontrados por estes autores estavam entre $0,253 \%$ e $0,325 \%$ de ácido cítrico, sendo condizentes com os observados neste trabalho, de $0,171 \%$ a $0,320 \%$ de ácido cítrico.

$\mathrm{O}$ pH mostrou-se afetado significativamente pelos tratamentos químicos e pelo tempo de armazenamento, não se observando interação significativa entre estes dois fatores. Os pedaços de manga tratados quimicamente não diferiram entre si em relação ao pH, mas apresentaram valores médios menores do que o controle. Isto evidencia que as soluções químicas foram efetivas em manter baixo os valores de $\mathrm{pH}$ (Tabela 2). Observou-se, ao longo do tempo de armazenamento, um ligeiro acréscimo nos valores médios do $\mathrm{pH}$, de 4,34 a 4,48 (Figura 1). Chantanawarangoon (2000) relatou que o $\mathrm{pH}$ dos pedaços de manga 'Kent' não sofreu modificações durante o armazenamento a $5^{\circ} \mathrm{C}$ por 9 dias.

Os sólidos solúveis totais (SST) são usados como indicadores de maturidade e também determinam a qualidade da fruta, exercendo importante papel no sabor. Os SST mostraram-se afetados de modo significativo pelos tratamentos químicos e pelo tempo de armazenamento, não havendo interação significativa entre estes dois fatores. Os teores de SST foram preservados mais eficazmente nos pedaços de manga tratados com ácido cítrico 1\% (Tabela 2).

Os pedaços de manga apresentaram variações pouco

TABELA 2 - Valores médios de pH, sólidos solúveis totais (SST), açúcares solúveis totais (AST) e vitamina C total de mangas 'Tommy Atkins' minimamente processadas.

\begin{tabular}{llccc}
\hline Tratamentos & $\mathbf{p H}$ & SST & AST & Vitamina C total \\
\hline Controle & $4,54 \mathrm{a}$ & $11,7 \mathrm{~b}$ & $7,65 \mathrm{ab}$ & $23,58 \mathrm{~b}$ \\
Ác. cítrico 1\% & $4,36 \mathrm{~b}$ & $12,1 \mathrm{a}$ & $7,97 \mathrm{a}$ & $23,05 \mathrm{~b}$ \\
Ác. ascórbico 1\% & $4,38 \mathrm{~b}$ & $11,4 \mathrm{c}$ & $7,38 \mathrm{~b}$ & $88,96 \mathrm{a}$ \\
$\mathrm{CaCl}_{2} 1 \%$ & $4,36 \mathrm{~b}$ & $11,5 \mathrm{bc}$ & $7,81 \mathrm{ab}$ & $23,04 \mathrm{~b}$ \\
\hline
\end{tabular}

Médias seguidas de mesma letra na coluna não diferem entre si, pelo teste de Tukey $(\mathrm{p}<0,05)$ expressivas em relação aos teores de SST durante o período de armazenamento, mas com tendência decrescente após o quarto dia (Figura 2A). Esta queda nos SST provavelmente ocorreu devido ao consumo dos mesmos nos processos respiratórios. Este comportamento também foi verificado por Donadon et al. (2001) em mangas 'Tommy Atkins' minimamente processadas. Segundo Rattanapanone et al. (2001), os teores médios de sólidos solúveis das mangas 'Tommy Atkins' minimamente processadas não sofreram influência do tempo de armazenamento, permanecendo semelhantes aos iniciais.

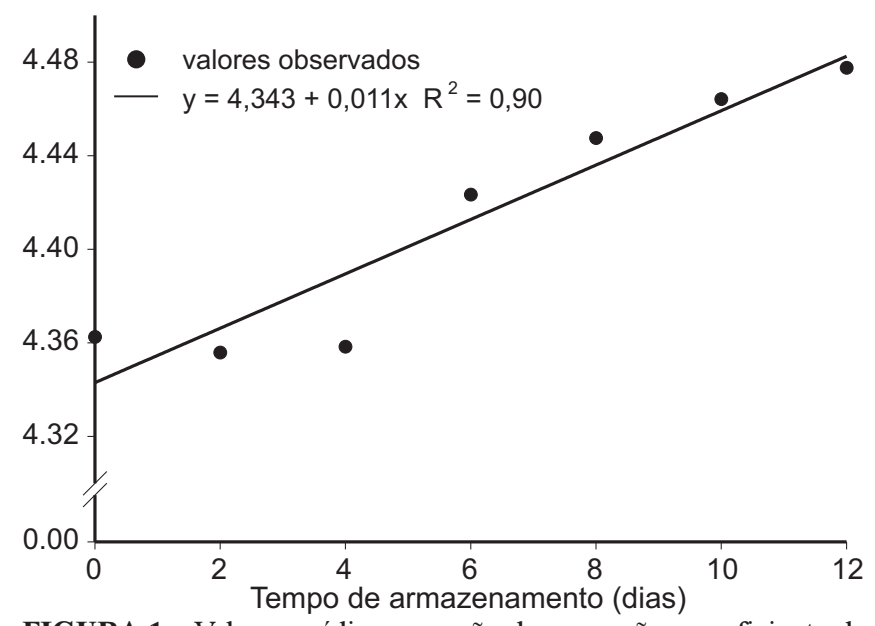

FIGURA 1 - Valores médios, equação de regressão e coeficiente de determinação de pH de mangas 'Tommy Atkins' minimamente processadas, submetidas a diferentes tratamentos químicos e armazenadas a $5 \pm 0,5^{\circ} \mathrm{C}$ e $80-90 \%$ UR, durante 12 dias.

Os fatores tratamentos químicos e tempo de armazenamento foram significativos para variável açúcares solúveis totais, não havendo interação entre estes dois fatores. O tratamento com ácido cítrico $1 \%$ promoveu maior retenção destes açúcares $(7,97 \%)$ em pedaços de manga, embora comprovada estatisticamente apenas com relação ao ácido ascórbico (7,38\%) (Tabela 2). O ácido cítrico é integrante do ciclo de Krebs, por isso provavelmente ocorreu menor gasto de açúcares com a respiração dos frutos.

Houve, inicialmente, redução nos teores de açúcares até o sexto dia de armazenamento (Figura $2 \mathrm{~B}$ ), provavelmente devido à sua utilização como substrato (respiração). Em seguida, sugere-se que tenha ocorrido síntese de açúcares até o final do armazenamento, possivelmente devido à interconversão amido-açúcar, de certa porcentagem remanescente de amido.

Houve efeito significativo dos tratamentos químicos e do tempo de armazenamento para a variável vitamina $C$ total, não se observando interação significativa entre estes dois fatores. Os pedaços de manga 'Tommy Atkins' foram eficientes em absorver o ácido ascórbico, o que determinou maior teor de vitamina $\mathrm{C}$ em relação aos demais tratamentos (Tabela 2). Segundo Chantanawarangoon (2000), o tratamento com $0,068 \mathrm{M} \mathrm{CaCl}_{2}+0,05 \mathrm{M}$ ácido ascórbico $+0,05 \mathrm{M} \mathrm{L}-$ cisteína por 2 minutos dobrou a concentração de ácido ascórbico total dos pedaços de mangas 'Haden' armazenados a $5^{\circ} \mathrm{C}$, situando-se na 

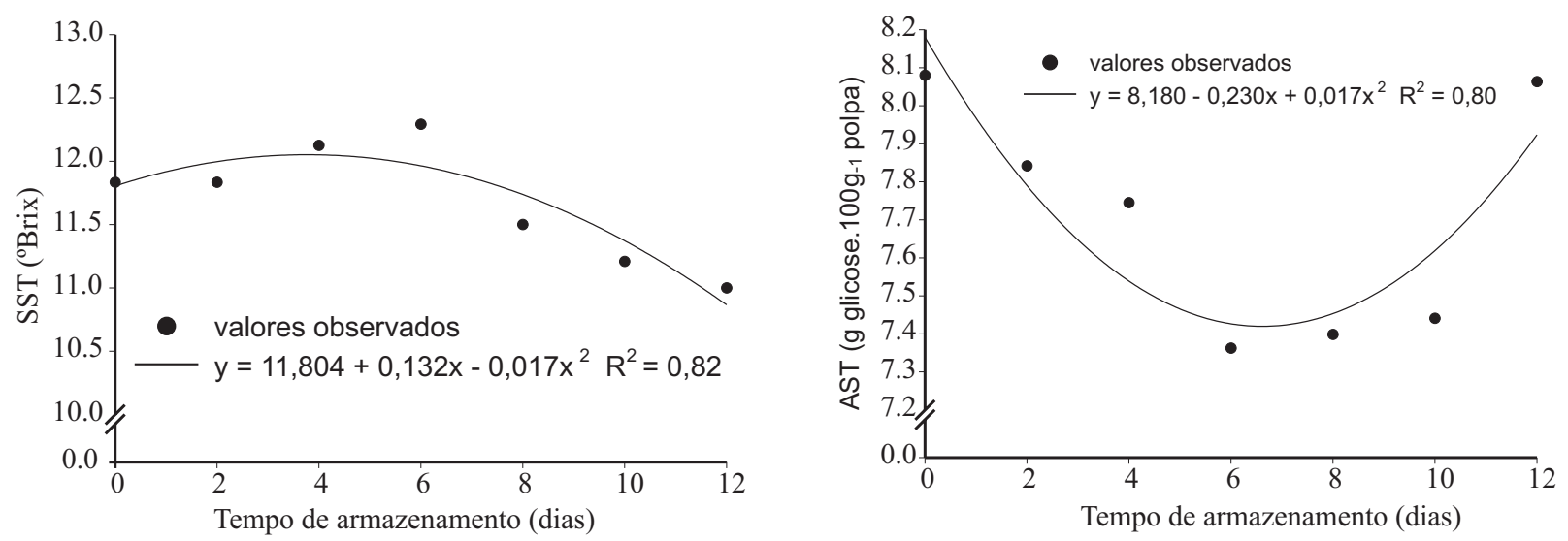

FIGURA 2 - Valores médios, equação de regressão e coeficiente de determinação de sólidos solúveis totais (A) e açúcares solúveis totais (B) de mangas 'Tommy Atkins' minimamente processadas, submetidas a diferentes tratamentos químicos e armazenadas a $5 \pm 0,5^{\circ} \mathrm{Ce} 80-90 \%$ UR, durante 12 dias.

faixa de $70 \mathrm{mg} .100 \mathrm{~g}^{-1}$ de polpa.

O teor de vitamina $\mathrm{C}$ total das mangas minimamente processadas manteve-se elevado até o sexto dia de armazenamento (Figura 3); a partir deste período, houve redução ao longo do armazenamento, indicando perdas de aproximadamente 10\%. Estas perdas podem estar relacionadas ao processamento mínimo, pois o corte dos tecidos aumenta a atividade enzimática e expõe os tecidos ao oxigênio. Os teores de ácido ascórbico mostraram tendência de redução ao longo do armazenamento dos pedaços de manga 'Tommy Atkins' embalados em copos plásticos e mantidos a $3^{\circ} \mathrm{C}$ por 14 dias, com perda de ácido ascórbico semelhante à verificada no presente trabalho (Donadon et al., 2001)

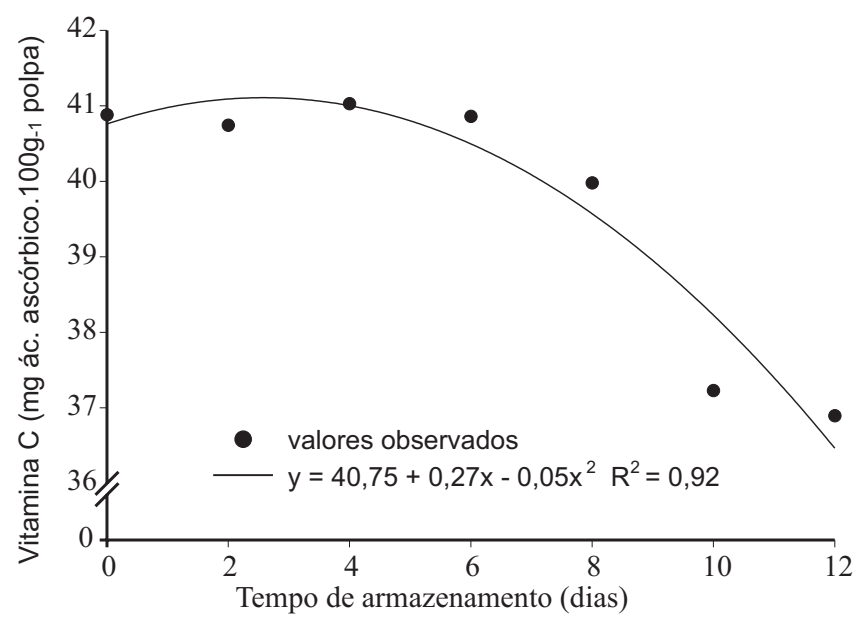

FIGURA 3 - Valores médios, equação de regressão e coeficiente de determinação de vitamina $\mathrm{C}$ total de mangas 'Tommy Atkins' minimamente processadas, submetidas a diferentes tratamentos químicos e armazenadas a $5 \pm 0,5^{\circ} \mathrm{C}$ e $80-90 \%$ UR, durante 12 dias.

A variável sabor mostrou-se afetada significativamente somente pelo fator tempo de armazenamento, não diferindo entre os tratamentos químicos. Ao longo do período de armazenamento, notouse redução linear nos valores das notas de sabor dos pedaços de manga, que mudaram de 7,64 para 6,19 (Figura 4). Observou-se que, no último dia de armazenamento, estes receberam notas entre "ligeiramente boa" (6) e "moderadamente boa" (7), indicando possivelmente a preservação deste parâmetro.

Constatou-se a presença de coliformes a $35^{\circ} \mathrm{C}$ nos pedaços de manga 'Tommy Atkins' somente no décimo e décimo segundo dias de armazenamento, sendo abaixo de 4,3 x $10^{1}$ NMP.g ${ }^{-1}$ polpa. Neste experimento, não foi detectada a presença de coliformes a $45^{\circ} \mathrm{C}$, estando de acordo com o padrão microbiológico especificado na Resolução RDC ํำ12, de 02 de janeiro de 2001, para frutas frescas, in natura, preparadas (descascadas ou selecionadas ou fracionadas), sanificadas, refrigeradas ou congeladas, para consumo direto (Brasil, 2001).

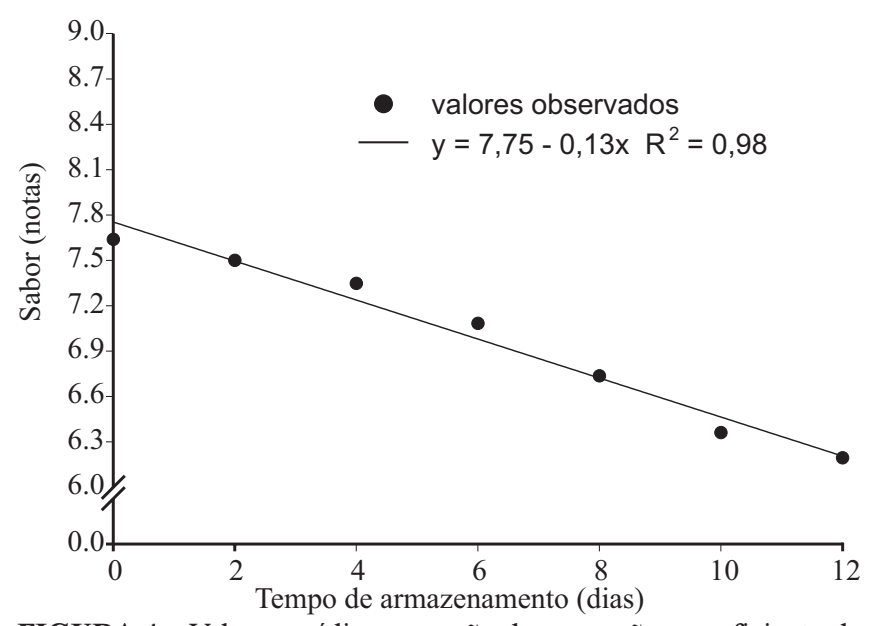

FIGURA 4 - Valores médios, equação de regressão e coeficiente de determinação de sabor de mangas 'Tommy Atkins' minimamente processadas, submetidas a diferentes tratamentos químicos e armazenadas a $5 \pm 0,5^{\circ} \mathrm{C}$ e $80-90 \%$ $\mathrm{UR}$, durante 12 dias.

Observou-se baixa contagem de fungos filamentosos e leveduras apenas no décimo e décimo segundo dias de armazenamento, independentemente do tratamento químico usado, sendo inferior a 1,1 $\mathrm{x} 10^{2} \mathrm{UFC} \mathrm{g}^{-1}$ de polpa, o que pode ser atribuído à contaminação ambiental durante o processamento mínimo e o armazenamento. A superfície do produto durante as etapas do processamento é exposta ao ar, havendo possível contaminação por bactérias, fungos filamentosos e leveduras.

Pode-se concluir que os tratamentos com ácido cítrico $1 \%$, ácido ascórbico $1 \%$ e cloreto de cálcio $1 \%$, indistintamente, não influenciaram na vida de prateleira das mangas 'Tommy Atkins' minimamente processadas, embora sejam eficazes em manter baixo o $\mathrm{pH}$ em relação ao controle. As mangas minimamente processadas, submetidas à atmosfera modificada ativa $\left(5 \% \mathrm{O}_{2}+5 \% \mathrm{CO}_{2}\right) \mathrm{e}$ armazenadas por até 12 dias a $5^{\circ} \mathrm{C}$, são consideradas seguras e de boa aceitação, desde que obedecidas as boas práticas de fabricação. 


\section{REFERÊNCIAS}

ASSOCIATION OF OFFICIAL ANALYTICAL CHEMISTRY. Official methods of analysis of the Association of Official Analytical Chemistry. 12.ed. Washington, 1992. 1015p.

BRASIL. Ministério da Saúde. Agência Nacional de Vigilância Sanitária. Resolução no 12, de 02 jan. 2001. Regulamento técnico sobre os padrões microbiológicos para alimentos. Disponível em: $<$ http://www.anvisa.gov.br/legis/resol/12_01rdc.htm>. Acesso em: 22 jan. 2003.

CANTWELL, M. I.; SUSLOW, T. V. Postharvest handling systems: fresh-cut fruits and vegetables. In: Kader, A. A. (Ed.) Postharvest technology of horticultural crops. 3th ed. Davis: California, 2002. cap. 36, p. 445-463.

CHANTANAWARANGOON, S. Quality maintenance of fresh-cut mango cubes. 2000. 72f. Thesis (Master of Science in Food Science) - University of California, Davis, 2000.

CHITARRA, M. I. F. Processamento mínimo de frutos e hortaliças Lavras: UFLA/FAEPE, 2000. 113p.

DISCHE, Z. General color reactions. In: WHISTLER, R. L.; WOLFRAM, M. L. Carbohydrate chemistry. New York: Academic Press, 1962. p. 477-512.
DONADON, J. R.; DURIGAN, J. F.; SARZI, B.; LIMA, M. A. Conservação de produtos minimamente processados de mangas 'Tommy Atkins' e 'Parvin'. In: CONGRESSO BRASILEIRO DE FISIOLOGIA VEGETAL, 8., 2001, Ilhéus. Anais... Viçosa: Agromídia, 2001. 1 CD ROM.

IFPA. 2002. International fresh-cut produce association. Disponível em: $<$ http://www.fresh-cuts.org > . Acesso em: 25 fev. 2003.

INSTITUTO ADOLFO LUTZ. Normas analíticas, métodos químicos e físicos para análise de alimentos. 3.ed. São Paulo: Instituto Adolfo Lutz, 1985. v. 1, 533p.

INTERNATIONAL COMMISSION ON MICROBIOLOGICAL SPECIFICATIONS FOR FOODS - ICMSF. Microorganisms in foods. 2 th ed. Toronto: University of Toronto, 1982. 436p.

RATTANAPANONE, N.; LEE, Y.; WU, T.; WATADA, A. E. Quality and microbial changes of fresh-cut mango cubes held in controlled atmosphere. HortScience, Alexandria, v.36, n.6, p. 10911095, Oct. 2001.

STROHECKER, R.; HENNING H. M. Analisis de vitaminas: metodos comprobados. Madrid: Paz Montalvo, 1967, 428p. 